$10 \mathrm{IKC}-067$

\title{
THE WAY OF THE DIAMOND PLACERS OF SOUTH-WESTERN AFRICA CAME INTO BEING
}

\author{
A. M. Lyukhin \\ Russian state geological prospecting university, Moscow, Russian Federation
}

\section{INTRODUCTION}

The coastal part of S.W. Africa happens to be a unique natural basin where all kinds of diamond placer deposits: marine, coastal-marine, alluvial and wind-borne are occurred. The problem of the initial sources of diamond placers and ways of diamond transportations and distributions within these large territories still remain to debate.

Based on geological evidences, the author explains the origin of these placers in the framework of impact hypothesis of diamonds and diamondiferous rocks formation (Lyukhin, 2008).

\section{BASIC PRINCIPLES OF THE IMPACT HYPOTHESIS}

Diamonds have been formed about 3.5 billion years ago when the Solar system passed throughout spout jets of Galaxy and the tenth planet of the Solar system, Phaeton, collided with one of these spout jets.

The beginning of diamond growth occurred at the moment of sharp jump pressure, when spout jets got a contact with Phaeton surface; diamonds continued to growth in turbulent environment feeding by influents hydrocarbon substances that delivered from Phaeton surface with huge speed. Because of gigantic spout jets pressure, Phaeton was displaced from its orbit and exploded, as results, abundance of various composition asteroids have been created, some of them were saturated by diamonds, and, apparently, synthesis of various chemical compounds from $\mathrm{H}, \mathrm{C}, \mathrm{O}, \mathrm{N}$ gases due the live derivation on the Earth, and giant-planets formation occurred.

Kimberlite pipes and dykes formed under closer to vertical asteroid impacts to the Earth, thus the form of frontal asteroid's surface have the main force. Asteroids have uneven surface with cavities and craters; additional surface fractures form during aerodynamic disintegration when asteroids passing through dense Earth's atmosphere. Cumulative effect exactly originated at the expenses of these asteroid surface features at the moment of touching of Earth's surface. It came out in derivation high-speed jets of strongly compressed asteroid's substances burned the Earth's surface and created pipe and dyke bodies.
Thus, kimberlite field represents a positive print of frontal asteroid's surface, where a pipe and dyke correspond to cavity (crater) and open toward Earth's surface fractures, respectively.

Kimberlite is filing pipe materials formed as a result of an impact crater creation and represented a mixture of shock-formed melt and crushed asteroid- and crater-hosting rocks. When diamantiferous asteroid collided with Earth at some angle, diamond dispersed on extended territories and later concentrated in different type of placers (for example South-West African places).

\section{THE SHORT CHARACTERISTIC OF S.W. AFRICAN DIAMOND PLACERS}

The coastal-marine placers extend from the northern end of the St. Helena Bay in South African Republic (SAR) to the Conception Bay in Namibia in the form of narrow along-shore terraces composed of gravel-pebbly formations with elevation from 0 up to $160 \mathrm{~m}$ above the sea level. In the zone between the Conception Bay and the Huab River mouth the diamonds are not available. A few coastal-marine deposits in the Quaternary terrace formations occurring at elevations from 5 up to $23 \mathrm{~m}$ above the sea level are known to be found north of the Huab River. They are characterized by extraordinary heterogeneity, an occurrence of gravellypebbly rocks, low diamond concentrations and small diamond sizes (0.1-0.2 carat/stone). In the alluvial gravel of the Huab and Unjab Rivers the diamonds have not been discovered.

The marine placers are much similar to the shore ones in the lithology and genesis. The extend northward to the island of Hollandsbird (240 km NNW of Luderitz). Several terrace surfaces running parallel with the shore line, elevation marks being 20,40 and 120-130 m below the sea level, have been mapped.

The wind-borne placers stretch along the coastal strip of Namibia from Granietberg to the Conception Bay in the linear zones and eolian transport corridors of northern strike. The width of the corridors is from 1 to $2 \mathrm{~km}$. Three wind-borne placers not associated with any distinctly delineated eolian transport corridors are also known.

The alluvial placers are confined to the Orange River down-stream valley as well as to more shallow rivers of 
Namaqualand. The diamondiferous pebbles of these rivers rather resemble poorly sorted depositions of temporary mud flows coming about in the periods of disastrous heavy rain falls.

All the diamonds founded on the coast of south-western Africa are rather alike. The distinguishing feature of herein spread diamonds accounts for their high jewelry quality and large size. The average mass of diamonds fluctuates from 0.1 to 1 carat. Smooth rounded stones predominate. A great number of diamonds bear traces of erosion and shocks ring-like potholes, hollows; crystals' edges and tops are rounded. A large number of fragments are any characteristic feature. Crystal twins and borts are few.

The size of stones along the Namaqualand coast makes $0.6-0.8$ carat/stone on the average and reaches its maximum in the area of the Orange River's mouth where it makes about 1 carat/stone, and gradually decreases northwards where in the area of Hottentot's Bay it makes 0.25 carat/stone, but in the areas of the Meob Bay and Conception Bay - already 0.07-0.1 carat/stone.

Most diamond concentrations are associated with Pleistocene-Holocene depositions and also with the upper parts of a section of older deposits. Meanwhile the richest diamond fields are developed essentially on the northern banks of gulfs opened southwards. The quality and content of pay component in diamondiferous gravel were initially checked by means of sample collection in the uppermost layer. So, the diamond-bearing placers of Pomona were phenomenally rich only on the surface.

According to modest calculations the total reserves of diamonds along the western coast of South Africa and the continental shelf account for 1.5 billion carats.

Today there is considered that diamonds from the kimberlite Provinces (Transvaal, Kimberley and others) having been carried by the Orange River to the sea coast for 35-40 million years and these diamonds found in most probable native sources of the coastal-marine deposits. However a considerable remoteness of highly diamondiferous kimberlite fields (about $1000 \mathrm{~km}$ ), a practically complete absence of diamonds in the Orange River depositions within a $500-\mathrm{km}$ cut-line as well as a very short-termed (in geological terms of time) formation of placers of different genetic types (coastal-marine, windborne and alluvial) within fairly vast territory (more than $800 \mathrm{~km}$ along the coast) and some other data make this assertion doubtful and leave open the issue of a diamonds source of these placers.

The Benguela current streaming along the western coast of South Africa is rather slow making $17 \mathrm{~cm} / \mathrm{sec}$ and has an equatorial direction. Hence, this current is not much powerful to influence the redistribution of diamonds in the continental shelf. The high-low tides did not also play a considerable role in the evolution of marine diamondiferous depositions because the western coast is an area of preferential waves with a high tide mark less than $2 \mathrm{~m}$.

\section{THE POSSIBLE SCENARIO OF S.W. AFRICAN DIAMOND PLACERS FORMATION}

The above-mentioned data, apart from the observations obtained in the study of alluvial placers in the Orange River down-stream and apart from the hypothesis of impact origin of diamonds being elaborated by the author, make it possible to reconstruct the following scenario of origination of diamondiferous placers in this region.

A large (about $5 \mathrm{~km}$ in diameter) diamondiferous asteroid has been collided with the Earth. This event took place in the Quaternary age, most probably between Pleistocene and Holocene $\left(Q_{\text {III }}^{4}-Q_{\text {IV }}{ }^{1}\right)$ at the coastal part of the Atlantic Ocean $150 \mathrm{~km} \mathrm{NNW}$ of Cape-town. This asteroid's flight performed from Antarctica towards N.N.W. direction at oblique (less than $10^{\circ}$ ) angle. As a result of oblique impact, an oval crater (St. Helena Bay) came into being, and large territories (from St. Helena Bay on the South to Conception Bay on the North) became covered with depositions of shock outbursts (including diamonds) (Fig. 1). So, diamonds dispersed on large territories were concentrated by various natural water and wind processes

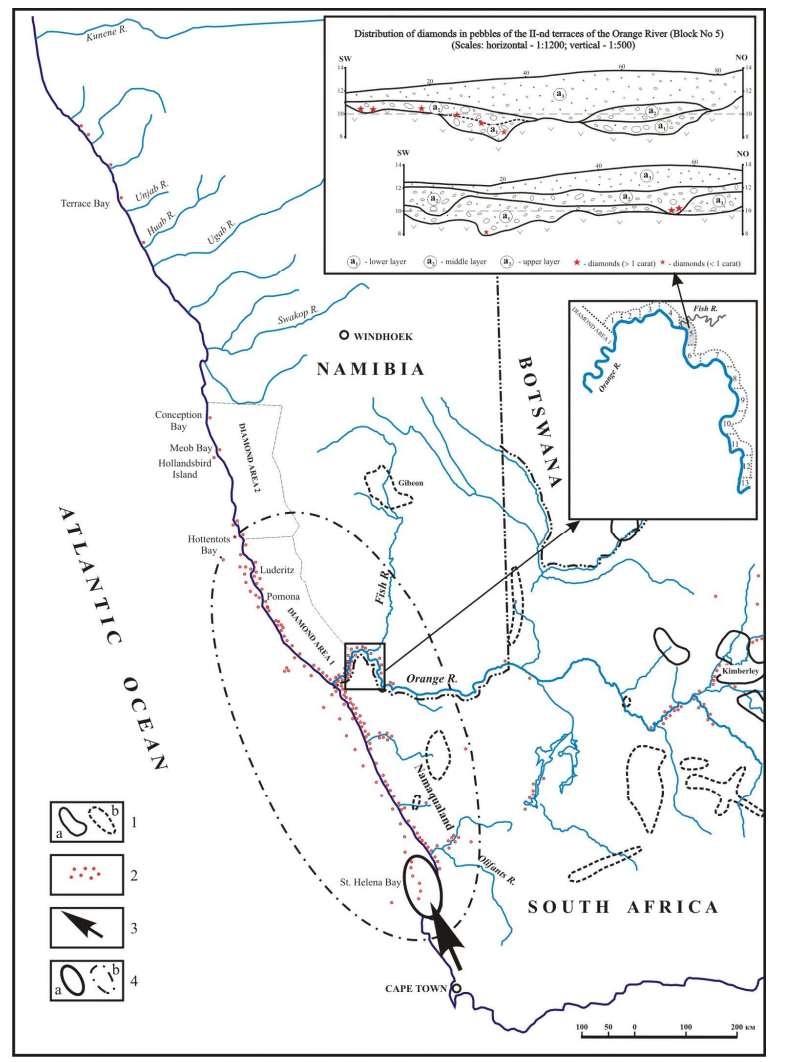

Fig. 1. The scheme of location of bedrock and placer manifestations of diamonds in the western part of South Africa. (The inset smaller map shows the location of blocks in the Orange River down-stream).

1 - Kimberlite fields (a - diamondiferous, b - non-diamondiferous); 2 Diamond placers; 3 - asteroid's flight direction; 4 - The assumed: shock crater (a), halo of distribution of outbursts depositions (b). 


\section{$10^{\text {th }}$ International Kimberlite Conference, Bangalore - 2012}

into placer deposits of different genetic types: marine, coastal-marine, alluvial and wind-borne ones.

The author indicates on geological and mineralogical evidences of the process of an impact collision when during the impact the terrestrial rocks experienced thermal metamorphism, disintegrated, and the matter of the intruder (hitter) intermingled with marine sedimentary rocks of the target and was scattered for a long distance at the stage of excavation. These explain the absence of marine sediments in coastal shelf along Namaqualand shore.

The presence of water during the impact process leads to fluid flow of ejecta matter fragments (similar to mud streams) and increases noticeably its mobility. In this fluid flow a partial dissolution of diamond crystals took place what was expressed in the rounding of faces and flattening of edges and tops as the initial warmed-over diamond crystals were etching in the atmosphere. The loss of diamonds weightes sustained during this short-term flight (approximately tens minutes) was insignificant but sufficient enough to completely dissolve small diamonds what explains their almost absolute absence in the placers as well as the north-trended decrease of a size of the stones that underwent greater dissolution in the longer air transportation.

The majority of diamonds mined on the marine terraces are covered with a hydrophilic coats composed of soluble salts of iron, chlorides and sulfates. These coats derived when the crystals, warmed-over to several hundreds degrees, were falling into the ocean, due to the adhesion of products of salt water evaporation to crystals' surfaces.

Exact diamond concentration in falling asteroid could not be determined, however, it is known that diamond concentration in diamondiferous stone meteorites-ureilites sometimes exceeds $1 \%$ of total meteorite mass, actually with a concentration of 1 carat $/ \mathrm{m}^{3}$ the simple arithmetic calculation gives a figure of 6.5 billion carats which probably can carry falling asteroid and more than $1 / 3$ of these diamonds were dispersed on S.W. African territories should be deposited on the shelf.

One of the signs testifying to an availability of outbursts depositions is the presence on the surface of outliers of the III-d and IV-th terraces in the Orange River down stream (Blocks 2, 3, 4, 5), rounded, angular-rounded, oval, lumplike formations with characteristic surfaces of type of "sea ripple" and "bread crust" represented by metamorphosed sedimentary rocks (from argillites to gritstones), that by a degree of fragmental material sorting could be referred to marine depositions (Fig. 2). They are rather evenly distributed in an area $\left(\approx 1\right.$ stone per $\left.1-4 \mathrm{~m}^{2}\right)$ and are encountered exclusively on the surface among common pebbles. The sizes of these formations for argillaceous and aleurolitic differences make from 1 up to $20 \mathrm{~cm}$, for sandy ones - up to $40 \mathrm{~cm}$. The surfaces of a similar type could have been formed as heated rock fragments were being rapid cooled at the place of the fall. Likewise formations but already with relicts of similar surfaces, or completely rounded ones are sometimes observed among alluvia of the 1 -st terraces of the Orange and Fish Rivers. The Karroo system sedimentary rocks outcrop onto the surface $50 \mathrm{~km}$ up the Orange River, and under the transportation in the water flow for this distance the surfaces of such a type could not have been retained with them.

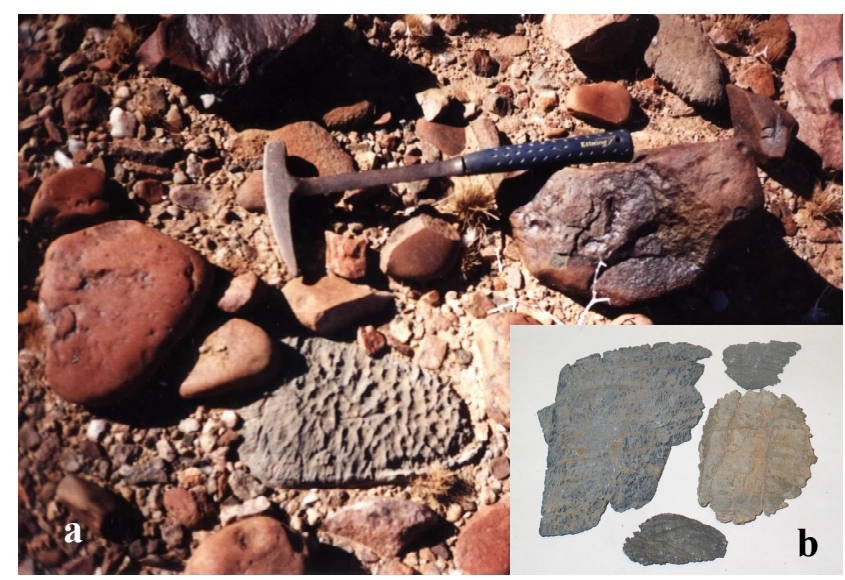

Fig. 2. The "alien" pebbles (a) on the surface of outliers of the IV-th terraces in the Orange River (Block No. 5) and their forms (b).

An increased number of discoveries of iron meteorites on the territory of Namibia that happened to be an inconsiderable constituent part of the fallen space body also find their explanation.

One may connect the time of the impact event with the beginning of formation of the middle horizon of alluvial deposits of the II-nd terraces in the Orange River downstream. The prospecting-assessment operations (Istomin and Lyukhin, 2000) have resulted in the conclusion that the lower layer is associated with only single small diamond crystals, but most diamonds are found in the medium layer predominantly in such places where it directly lies on the bedrock. The diamonds founded in this layer have larger sizes (up to 10 carats and more) and their concentration reaches a value for profitable mining. The high concentration of diamonds, sharp difference of the petrographic composition of a fragmental product from the lower horizon and, especially, from the depositions of the Ist and IV-th terraces, a considerably increased (2-4 times as many) outcome of the heavy concentrate samples, an availability in the samples exclusively from this horizon of minerals of ultrabasic paragenesis with such nimerals as chrom-spinellides, olivine, picroilmenite and pyrope, having different roundness and good state of preservation testify to the fact that a favorable situation for accumulation of diamonds in the pebbles did exist in the moment of the middle layer formation. One may only explain such alterations by a superimposed geological process since the Orange River did not change its channel at this time. The formation of the II-nd terraces in the Orange River downstream is likely to have taken place in the following way. 


\section{$10^{\text {th }}$ International Kimberlite Conference, Bangalore - 2012}

At the beginning the base level of erosion of the river was low, and the valley got developed with simultaneous accumulation of the lower layer of alluvial depositions. The beginning of the middle layer formation was prompted by the fall of a space body as a result of which the depositions of outbursts (including diamonds) had covered an enormous territory. As a result of displacement (movement) of an immense amount of stone material the Orange River in its down-stream appeared to be "dammed" in several places what testified to a cascade setting of its channel according to which the accumulation of alluvium took place at different hypsometric levels. The fragmentally distributed thick (more than $10 \mathrm{~m}$ ) strata of gravelly-sandy material on the outliers of the II-nd terraces in the river down-stream testify to that. The differences of petrographic composition and diamond potential in these layers are explained by a removal from the slopes and a washout of "alien" depositions of shock outbursts representing the products of thermal metamorphism of marine sedimentary rocks and, rather seldom, disintegrated rocks of a space body of ultrabasic composition. The process of the middle layer formation was rather short in terms of time to what testifies a small and matured thickness of the depositions. This process continued until the river had broken through "dams" in its down-stream. The local base level of river erosion was sharply lowered and the river went aside to run its recent channel having completed the formation of the IInd terraces thereby.

\section{CONCLUSION}

The knowing of the deposit genesis is the key for its searches. The corroboration of the suggested hypothesis will make possible to approach to the prospecting for and assessment of placer diamond deposits on this territory more comprehensively and purposefully. For corroboration of this hypothesis it is possible to make a simple experiment.

It is necessary to take some pure diamond crystals to heat them up to a few hundreds degrees and sink them into sea-water; as a result, the films similar those on the diamonds taken from the placers of Southwest Africa would be formed on the surfaces of experimental crystals.

The market of natural gem quality diamonds, which beauty are represented huge value from ancient ages, in the view of new hypothesis of its cosmic origin indicating that diamonds incoming from space bear positive energy and have very romantic history, will very strongly increases and definitely gives huge commercial success.

Everything in nature is interconnected. The collisions of the Earth with large space bodies lead to serious geological disasters, such as a displacement of the Earth's rotation axis; inversion of the Earth's magnetic field; global climate change etc. Should asteroids plunge into an ocean thetsunami waves will fall in the coasts, and trillions of tons of water will get evaporated as a result of the heat released.
These evaporations would later come about in the form of heavy rain falls. Therefore it is most probable that the assumed impact event has caused Atlantida to collapse resulting from a gigantic tsunami what took place, after Plato, approximately at the same time - 11500 years ago, and led to the global warming of the Earth's climate that also begun at the boundary of Pleistocene and Holocene. The Ozone Hole formation above Antarctic continent is also a result of this event.

\section{References}

Istomin, V. and Lyukhin, A. (2000) Diamondiferous alluvial deposits of Block No. 5 (the Orange River) (Report on the results of prospecting and assessment works within Concession "Block No. 5"). Namibia, Windhoek.

Lyukhin, A., (2008) The Hypothesis of Impact Origin of Diamonds and Kimberlites. $9^{\text {th }}$ International Kimberlite Conference Ext. Abs 9IKCA- 00080 .

Contact: Alexey Lyukhin, Email: lyuhin@yandex.ru 